\title{
Aplicação do índice de qualidade da água no rio Ipixuna e avaliação das condições de balneabilidade com a percepção ambiental dos usuários
}

Application of the water quality index in the Ipixuna river and evaluation of bathing conditions with the users' environmental perception

Aplicación del índice de calidad del agua en el río Ipixuna y evaluación de las condiciones de baño con la percepción ambiental de los usuarios

\author{
Celiane Lima dos Santos \\ ORCID: https://orcid.org/0000-0002-6594-4630 \\ Universidade do Estado do Pará, Brasil \\ E-mail: celianelima.eng@gmail.com \\ Maria Renata da Rocha Xavier \\ ORCID: https://orcid.org/0000-0001-7610-9668 \\ Universidade do Estado do Pará, Brasil \\ E-mail: renatarochax@hotmail.com \\ Denison Lima Correa \\ ORCID: https://orcid.org/0000-0002-2561-7758 \\ Geo Agro Consultoria Ambiental, Brasil \\ Email: denison.singeo@gmail.com \\ Antônio Pereira Junior \\ ORCID: https://orcid.org/0000-0001-6241-985X \\ Universidade do Estado do Pará, Brasil \\ E-mail: antonio.junior@uepa.br
}

\begin{abstract}
Resumo
Os Índices da Qualidade da Água (IQA) e de Condições da Balneabilidade (ICB), associados a percepção ambiental, podem designar as relações entre o homem e o meio ambiente aquático. O objetivo desta pesquisa foi analisar a qualidade da água e as condições de balneabilidade do Rio Ipixuna, em Ipixuna do Pará. O método utilizado foi o quanti-qualitativo. Para O IQA: realizaram-se duas coletas em dois períodos (seco e chuvoso); Para ICB, 25 amostras de água em cinco pontos distintos, durante cinco semanas consecutivas. Os dados obtidos e análise dos dados obtidos indicaram que o IQA apresentou pouquíssimas variáveis em desacordo com o contido na Resolução CONAMA $357 / 05$ como, por exemplo, $\mathrm{pH}(\bar{x}=5,54)$; Ptotal $(\bar{x}=0,1 \mathrm{mg} / \mathrm{L})$ e Ntotal $(\overline{\mathrm{x}}=1,58 \mathrm{mg} / \mathrm{L})$, todavia não comprometeram a qualidade dela; em relação ao ICB, a análise dos dados obtidos indicou que todos os pontos amostrais apresentaram classificação imprópria para balneabilidade com necessidade de suspensão do uso através de sinalização temporária, amostragem diária da água e identificação da origem da contaminação. Em relação aos valores de $E$. coli, eles situaram-se entre 50>500 UFC/100 mL, em todos os pontos de coleta estudados, logo, água com subcategoria "excelente", "muito boa" e "satisfatória". Quanto a percepção ambiental, quase a metade $(n=49 ; 44,54 \%)$ dos indivíduos amostrados afirmaram que a qualidade da água é ruim; os demais $(n=54 ; 49,08 \%)$ sentiram algum desconforto: irritações na pele e olhos, após a prática do banho. Portanto, controle da qualidade da água do rio Ipixuna, deve ser efetuada pelo menos a cada semestre para assegurar o bem-estar da população do município e a qualidade ambiental.
\end{abstract}

Palavras-chave: Análise físico-química da água; Escherichia coli; Patógenos; Uso recreacional.

\begin{abstract}
The indices of water quality (IQA) and bathing conditions (ICB), associated with environmental perception, can designate the relationship between man and the aquatic environment. The objective of this research was to analyze the water quality and bathing conditions of the Ipixuna River, in Ipixuna do Pará. The method used was quantitative and qualitative. For the IQA: two samples were collected in two periods (dry and rainy); for ICB, 25 water samples were collected in five different points, during five consecutive weeks. The data obtained and analysis indicated that the IQA presented very few variables in disagreement with what is contained in the CONAMA Resolution 357/05 as, for example, $\mathrm{pH}(\bar{x}=5,54)$; Ptotal $(\bar{x}=0.1 \mathrm{mg} / \mathrm{L})$ and Ntotal $(\bar{x}=1,58 \mathrm{mg} / \mathrm{L})$, however they did not compromise its quality; In relation to the ICB, the analysis of the data obtained indicated that all sampling points presented improper classification for bathing with the need for suspension of use through temporary signaling, daily water sampling and identification of the source of contamination. Regarding the values of E. coli, they were between 50>500 CFU/100
\end{abstract}


$\mathrm{mL}$ in all sampling points studied, therefore, water with subcategories "excellent", "very good" and "satisfactory". Regarding environmental perception, almost half $(n=49 ; 44.54 \%)$ of the sampled individuals said that the water quality was bad; the others $(\mathrm{n}=54 ; 49.08 \%)$ felt some discomfort: skin and eye irritation after bathing. Therefore, control of the water quality of the Ipixuna River should be carried out at least every semester to ensure the well-being of the population of the municipality and the environmental quality.

Keywords: Physical-chemical water analysis; Escherichia coli; Pathogens; Recreational use.

\section{Resumen}

Los índices de calidad del agua (IQA) y las condiciones de baño (ICB), asociados a la percepción ambiental, pueden designar la relación entre el hombre y el medio acuático. El objetivo de esta investigación fue analizar la calidad del agua y las condiciones de baño del río Ipixuna, en Ipixuna do Pará. El método utilizado fue cuanti-cualitativo. Para el IQA: se realizaron dos recogidas en dos periodos (seco y lluvioso); para el ICB, 25 muestras de agua en cinco puntos diferentes, durante cinco semanas consecutivas. Los datos obtenidos y analizados indicaron que el IQA presentó pocas variables en desacuerdo con el contenido de la Resolución CONAMA 357/05 como, por ejemplo, $\mathrm{pH}(\bar{x}=5,54)$; Ptotal $(\bar{x}=0.1 \mathrm{mg} / \mathrm{L})$ y Ntotal $(\bar{x}=1,58 \mathrm{mg} / \mathrm{L})$, sin embargo no comprometieron su calidad; En relación con el ICB, el análisis de los datos obtenidos indicó que todos los puntos de muestreo presentaban una clasificación inadecuada para el baño con necesidad de suspensión del uso mediante señalización temporal, muestreo diario del agua e identificación del origen de la contaminación. En cuanto a los valores de E. coli, se situaron entre 50>500 UFC/100 mL en todos los puntos de muestreo estudiados, por lo que se trata de aguas con subcategorías "excelente", "muy buena" y "satisfactoria". En cuanto a la percepción ambiental, casi la mitad $(n=49 ; 44,54 \%)$ de los individuos de la muestra dijeron que la calidad del agua es mala; los demás $(n=54 ; 49,08 \%)$ sintieron algunas molestias: irritación de la piel y de los ojos después del baño. Por lo tanto, el control de la calidad del agua del río Ipixuna debe realizarse al menos cada semestre para garantizar el bienestar de la población del municipio y la calidad ambiental.

Palabras clave: Análisis fisicoquímico del agua; Escherichia coli; Patógenos; Uso recreativo.

\section{Introdução}

Em 1970, a Fundação Nacional Sanitária (National Sanitation Foundation) dos Estados Unidos desenvolveu estudos sobre a qualidade da água, cuja Companhia Ambiental do Estado de São Paulo (CETESB), adaptou e desenvolveu o Índice da Qualidade de Água (IQA). O Índice resulta em um número adimensional e exprime a qualidade da água para os diversos usos, por agregação de dados físico-químicos, bacteriológicos, onde a determinante principal é a utilização para abastecimento público. Logo, o termo qualidade da água ganhou ênfase, e não se restringiu apenas à determinação da pureza, mas também as interferências antrópicas e caracterização físico-química e biológica desejada para diversos fins (CETESB, 2017).

As primeiras preocupações com a poluição e a pureza do corpo hídrico foram realizadas na Alemanha em 1848. Já no Brasil, só começou a se desenvolver quando o Conselho Nacional do Meio Ambiente (CONAMA) manifestou a necessidade da utilização de índices para o meio ambiente (PNMA, 2008).

Tal preocupação foi em função da água representar, para o homem, um importante recurso para manutenção da vida, pois, além de ser vital ao funcionamento do organismo, ela também é uma importante fonte econômica, no qual são utilizadas na produção de alimentos, operações industriais, navegação, geração de energia, recreação, dentre outros. Porém, com o crescimento desordenado da urbanização e consequentemente grande geração de efluentes, e os despejos in natura em corpos hídricos durante décadas, o ambiente aquático natural foi cada vez mais prejudicado (Moura \& Fermino, 2014).

Além disso, a possibilidade de ingestão de água de contato primário pode causar efeitos desagradáveis, principalmente as águas recreacionais, que contêm geralmente uma mistura de microrganismos patogênicos/não/de vida livre (Scandelai et al., 2012).

Nestas circunstâncias, os usuários são expostos ao contato direto com microrganismos patogênicos que podem proliferar no organismo deles e proporcionar impacto negativo à saúde. No caso do contato primário tem-se o surgimento de dermatoses, conjuntivites, otites, dentre outras. No Brasil, o uso recreacional das águas requer monitoramento constante pare verificação do estado das águas com esta finalidade (Perdigão et al., 2018). 
Historicamente, os primeiros registros acerca da balneabilidade datam há 3000 anos antes de cristo, que retratam a época do império egípcio e início da era moderna que disseminou o banho e as termas (possuía a finalidade de banho, banheiro e centro de convívio social). Além disso, a balneabilidade estava vinculada a ideia de banhos religiosos, principalmente na cultura oriental (Campos \& Cunha, 2015).

Uma definição acerca desse assunto foi escrita a partir da Diretiva 76/160 da Comunidade Econômica Europeia (CEE), que definiu a balneabilidade como todas as águas correntes, águas doces e salgadas, em que o banho é autorizado pelas autoridades competentes vigentes, ou não é um ato proibido (Lopes et al.,2013).

Em relação à percepção ambiental, ela deve ser associada a presença dos indivíduos ao meio onde ele se encontra, realiza funções, reproduz e, para que haja o desenvolvimento de elo afetivo dele pelo local e aprenda a utilizá-lo e conservá-lo (Teixeira et al., 2020). Logo, ela é um ato de extrair informação, oriundo da assimilação e utilização do conhecimento (Rodrigues et al., 2012).

Ademais, o principal aspecto de percepção, são as relações entre o homem e o meio ambiente, como cada indivíduo percebe e conhece do seu próprio meio, o que ele espera e a forma que o utiliza, levando em consideração suas ações culturais. Visto que, as comunidades percebem os espaços e o tempo de forma diferente, de acordo com suas crenças, costumes, valores e necessidades (Macedo-Silva et al., 2016).

Então, o problema da qualidade da água e de balneabilidade ainda estão latentes e frequentes, e isso justifica essa pesquisa, e incrementa a relevância dela, além de permitir a elaboração dos objetivos: 1) avaliar a qualidade da água em comparação a Resolução n. 357 (Brasil, 2005); 2) Avaliar o Índice de Condição de Balneabilidade do rio Ipixuna em função da Resolução n. 274 (Brasil, 2000); 3) verificar a percepção acerca da qualidade da água dos banhistas nesse rio; 4) gerar dados que permitam aos órgãos competentes do município, ações de controle e mitigação dos problemas hídricos e ambientais aqui identificados.

\section{Material e métodos}

\subsection{Fisiografia do município}

A pesquisa foi realizada no munícipio de Ipixuna do Pará, especificamente no rio Ipixuna, situado à Mesorregião do Nordeste Paraense e à Microrregião Guamá, com uma área territorial de 5.215,555 km² e população estimada para 2017 de 62.237 pessoas (IBGE, 2010). De acordo com o banco de dados vetoriais da Secretária de Estado de Meio Ambiente e Sustentabilidade (SEMAS, 2018), o Rio Ipixuna está inserido na Bacia Hidrográfica do Rio Capim, é um rio que aflora e desagua dentro dos limites dessa localidade. Além disso, apresenta $62,29 \mathrm{~km}$ de extensão da nascente a foz e possui 93 tributários (Figura 1). 
Figura 1. Mapa hidrográfico da bacia do Rio Ipixuna, Pará.

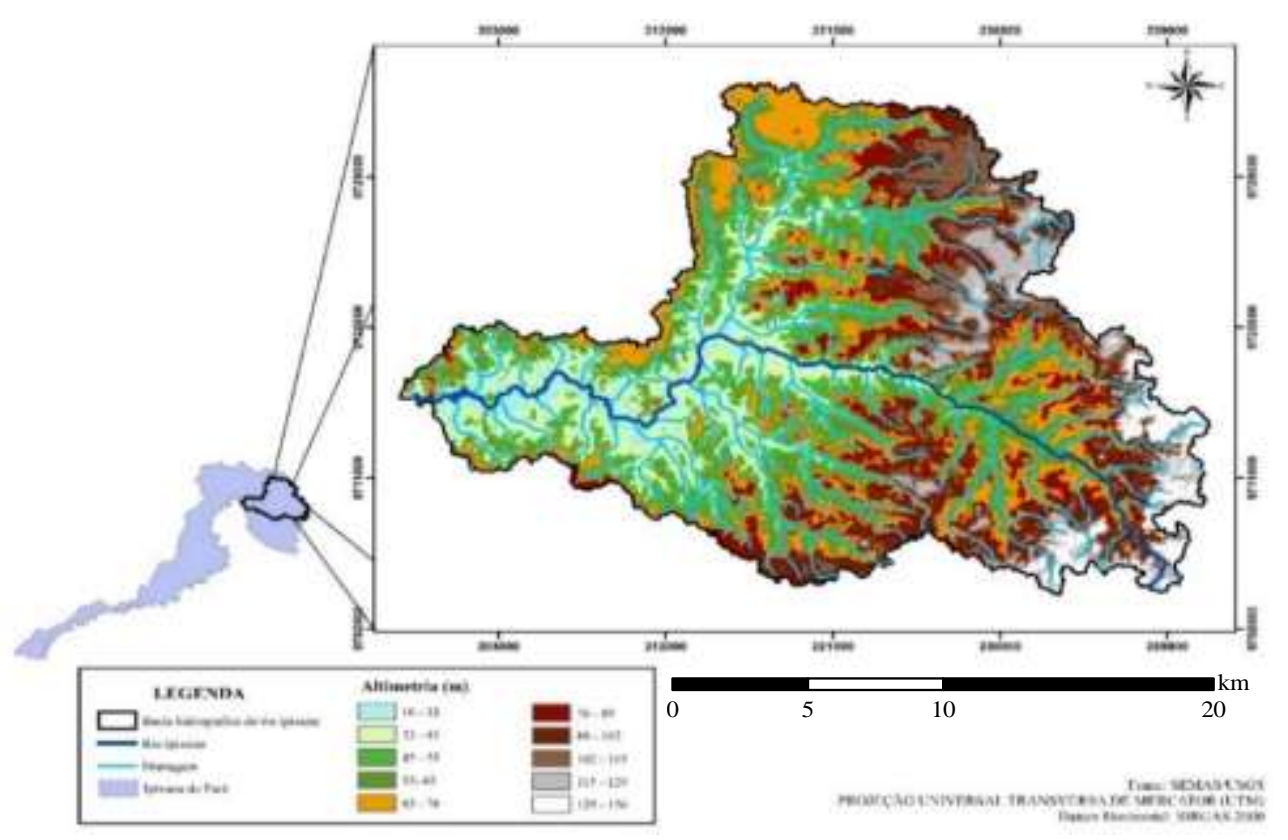

Fonte: Autores (2020).

A vegetação predominante são as florestas de várzea baixa com solo argiloso, possui uma precipitação pluviométrica média anual de 1750 a $2500 \mathrm{~mm}$. O uso e ocupação do solo de Ipixuna do Pará apresenta o seguinte cenário: 1) 31,61\% de floresta primária; 2) 9,85\% de floresta secundaria; 3) 33,21\% de área de agricultura, e 4) 15,34\% de pastagem (Cordeiro et al., 2017).

\subsection{Método}

O método adotado para essa pesquisa resultou de sínteses escritas (Quadro 1) por quatro pesquisadores que estavam concatenadas com o objetivo dessa pesquisa e, após leitura e seleção, foram adaptadas à necessidade expositiva de Resultados e discussão.

Quadro 1. Autores e sínteses utilizadas para composição do método empregado nessa pesquisa.

\begin{tabular}{|c|c|l|}
\hline Autor (es) & $\begin{array}{c}\text { Ano da } \\
\text { Publicação }\end{array}$ & \multicolumn{1}{c|}{ Síntese } \\
\hline Borges & 2014 & $\begin{array}{l}\text { Esse autor sintetizou que o método dedutivo se apoia em duas premissas verdadeiras, logo, a } \\
\text { conclusão também o é. Para essa pesquisa, as duas premissas utilizadas foram: 1) o despejo de esgotos } \\
\text { sem tratamento prévio em corpos hídricos, modifica a qualidade da água; 2) análises laboratoriais em } \\
\text { períodos pré-determinados pela Secretaria Municipal do Meio Ambiente (SEMMA), deve constar no } \\
\text { Plano Municipal de Gestão dos Recursos Hídricos. } \\
\text { Conclusão: o desague de efluentes e a escassez de análises laboratoriais frequentes, contribuem para a } \\
\text { Deteriorização da qualidade da água. }\end{array}$ \\
\hline Matias-Pereira & 2016 & $\begin{array}{l}\text { Abrangência quantitativa permite o uso de números para expressar dados. Isso permitiu o cálculo para } \\
\text { dois valores: IQA e ICB. Qualitativa adjetiva a quantidade obtida, que permitiu adjetivar a água do rio } \\
\text { Ipixuna, a partir do contido nas Resoluções CONAMA n. o 274 (BRASIL, 2000) e 357 (BRASIL, } \\
\text { 2005). }\end{array}$ \\
\hline Pereira et al. & 2018 & $\begin{array}{l}\text { Esse autores escreveram que o conhecimento é o referencial às pesquisas de cunho quantitativo e } \\
\text { qualitativo. Por isso, essa pesquisa tem cunho duplo, já que não foram evidenciados estudos com esses } \\
\text { dimensionamentos no rio Ipixuna. }\end{array}$ \\
\hline Sakamoto \& & 2014 & $\begin{array}{l}\text { Para estas duas autoras, a aplicação do conhecimento adquirido sobre o tema, permite a divulgação } \\
\text { dele. Esta é o foco dessa pesquisa que, após a publicação será encaminhada a SEMMA para } \\
\text { conhecimentos e providencias necessárias à melhoria da qualidade da água e balneabilidade do corpo } \\
\text { hídrico analisado. }\end{array}$ \\
\hline
\end{tabular}




\subsection{Pontos de amostragens}

A localização dos cinco locais utilizados para balneabilidade, tornaram-se os pontos para amostragem da água no rio Ipixuna (1,3 km, montante para jusante), e a base para essa escolha foi o maior número de frequentadores, após estimativa da população absoluta do local com auxílio de contador estatístico, como preconiza a Resolução CONAMA 274 (BRASIL, 2000). O primeiro ponto fica situado na área rural (PC01) do município, quanto aos demais (PC02, PC03, PC04, PC05) estão situados próximos ao centro urbano do município de Ipixuna do Pará, Pará (Figura 2).

Figura 2. Localização dos pontos de coletas de água superficial no rio Ipixuna, Pará, Brasil.

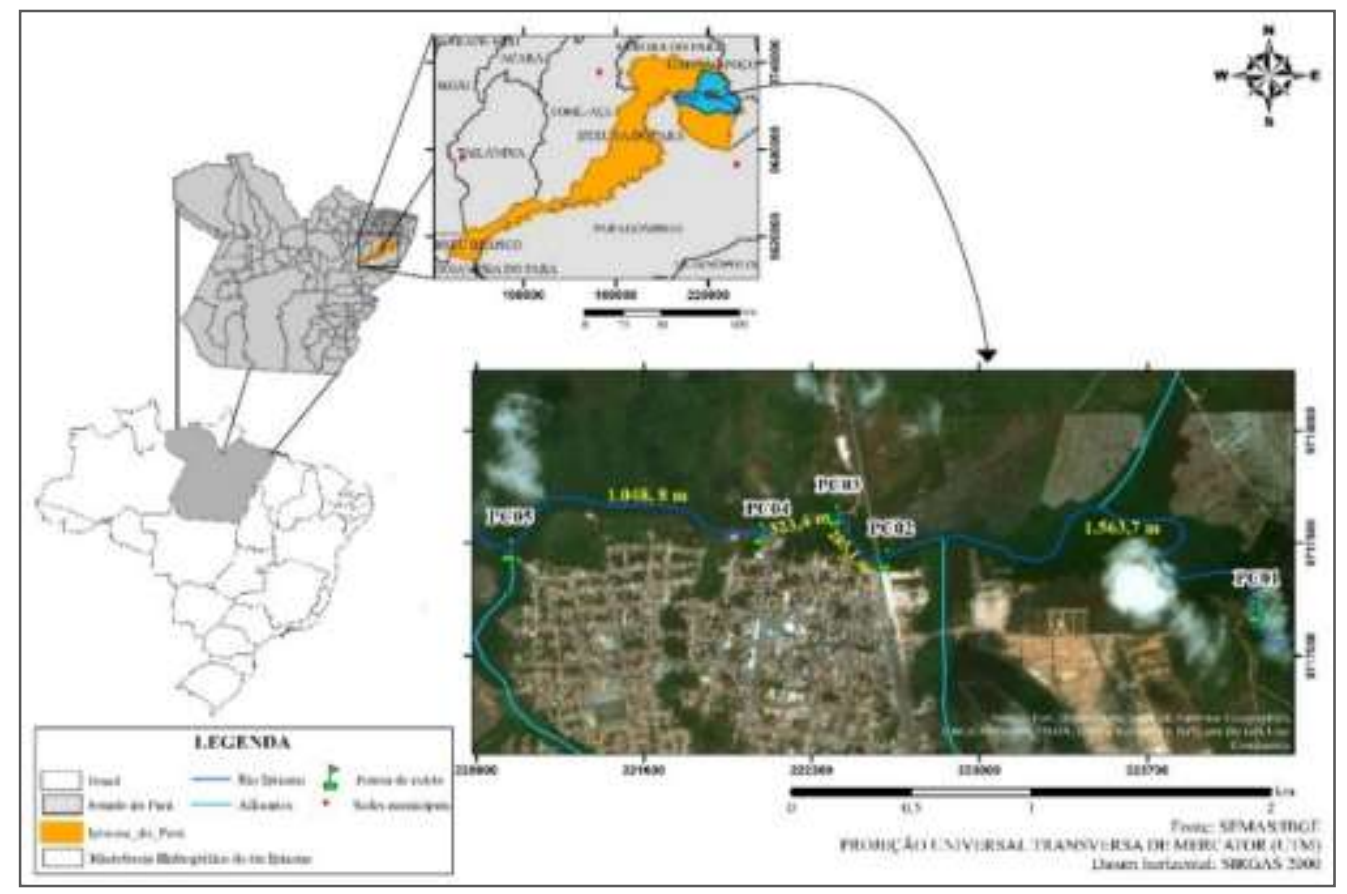

Fonte: Autores (2020).

O Ponto P1 (Figura 3a) para coleta de água superficial, situa-se na zona rural. Nota-se que há conservação da mata ciliar, e as comunicações entre as margens é realizada por uma ponte de madeira cuja conservação fica a cargo da comunidade agrícola. P2 (Figura 3b), situa-se logo após a ponte de concreto que perpassa por sobre o rio Ipixuna, na BR 010, a $500 \mathrm{~m}$ dela; P3 (Figura 3c), localiza-se no final na zona rural, onde a balneabilidade já é mais frequente. P4 (Figura 3d) e P5 (Figura 3e), já estão alocados na zona urbana. 
Figura 3. A) Ponto 1, ponte de madeira que permite a acessibilidade à margem oposta no rio Ipixuna, na zona rural; b) P2, a 500m de P1, zona rural; c), P3, A 500 m no sentido horizontal e do fluxo do rio em tela; d) P4, zona urbana, onde se verifica a formação de caneleta de escoamento da água superficial de área pavimentada; e) P5, área urbana com ponte de acesso, em madeira, para acesso ao rio.

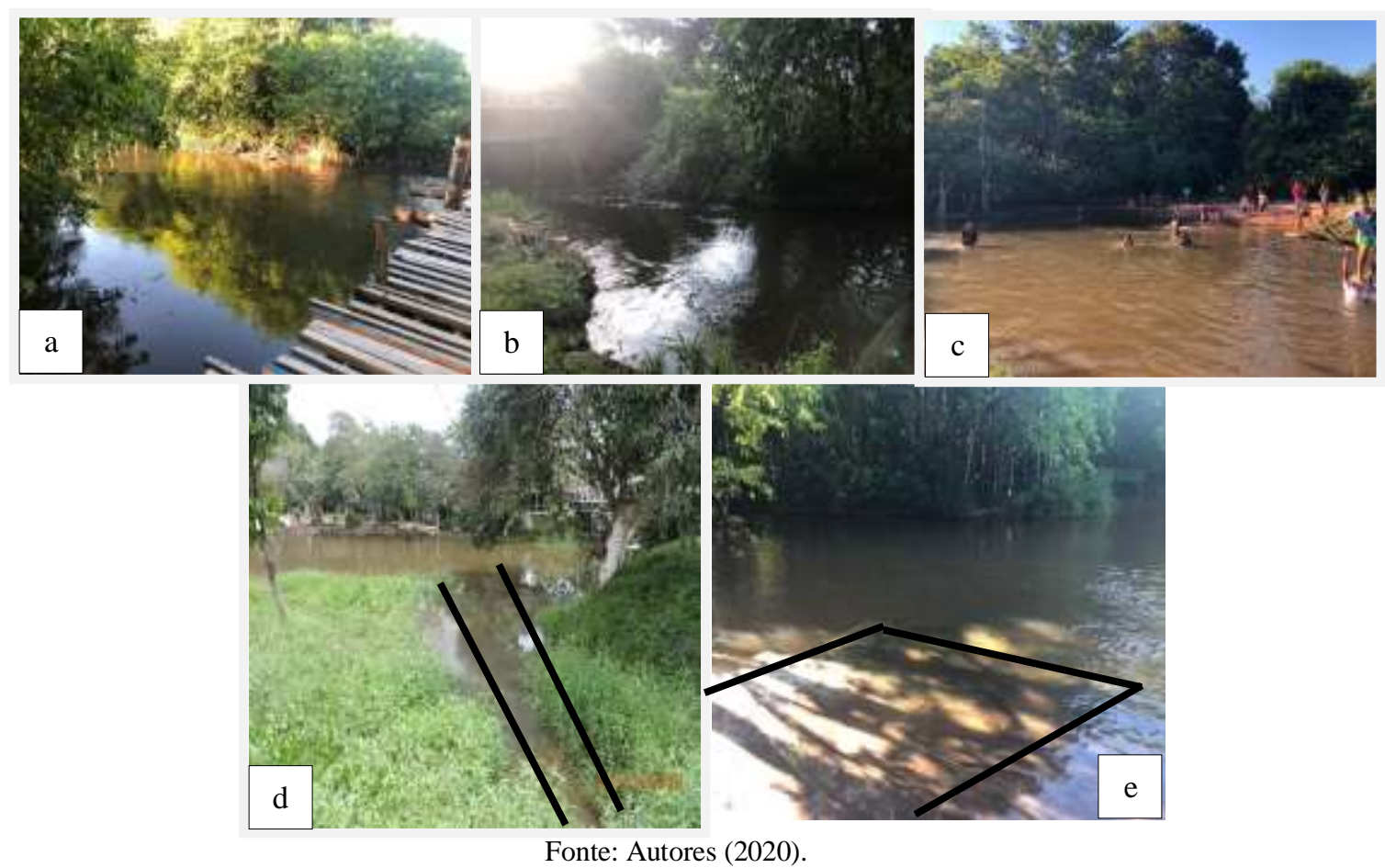

Nessa pesquisa, a extensão da "zona da mistura" em relação aos pontos de coletas, não foram consideradas porque o objetivo não foi identificar tal local e os tipos de efluentes, tratados ou não, e nem as vazões, que desaguam no rio Ipixuna. Em relação a localização via coordenadas geográficas e altimetria dos cinco pontos de coleta foram obtidos com o uso do receptor Global Positioning System - GPS, marca Garmin 62 S (Tabela 1).

Tabela 1. Dados dos pontos de coleta de água, Ipixuna do Pará. Pará.

\begin{tabular}{cccc}
\hline $\mathbf{P C}$ & Latitude $(\mathbf{S})$ & Longitude $(\mathbf{W})$ & Altimetria (m) \\
\hline $\mathbf{0 1}$ & $02^{\circ} 33^{\prime} 22,02839^{\prime \prime}$ & $47^{\circ} 28^{\prime} 50,21399^{\prime \prime}$ & 37 \\
$\mathbf{0 2}$ & $02^{\circ} 33^{\prime} 14,51879^{\prime \prime}$ & $47^{\circ} 29^{\prime} 40,25399^{\prime \prime}$ & 38 \\
$\mathbf{0 3}$ & $02^{\circ} 33^{\prime} 08,17560^{\prime \prime}$ & $47^{\circ} 29^{\prime} 46,98601^{\prime \prime}$ & 36 \\
$\mathbf{0 4}$ & $02^{\circ} 33^{\prime} 10,76401^{\prime \prime}$ & $47^{\circ} 29^{\prime} 57,13081^{\prime \prime}$ & 48 \\
$\mathbf{0 5}$ & $02^{\circ} 33^{\prime} 13,05720^{\prime \prime}$ & $47^{\circ} 30^{\prime} 30,98879^{\prime \prime}$ & 76 \\
\hline
\end{tabular}

Legendas: PC - Ponto de Coleta. Fonte: Autores (2020).

\subsection{Coleta de dados}

\subsubsection{Primários}

A percepção ambiental dos frequentadores dos balneários onde localizaram-se os pontos de coleta de agua foi obtida a partir da aplicação de 110 formulários semiestruturados (10 questões: cinco objetivas e cinco subjetivas) aos banhistas, em todos os pontos de coleta, distribuídos conforme o tamanho da amostragem: PC01 (15); PC02 (05); PC03 (30); PC04 (50); PC05 (10), acompanhados do Termo de Consentimento Livre e Esclarecido (TCLE), para atender as Resoluções 466 
(BRASIL, 2012) e 510 (BRASIL, 2016b). A determinação da amostragem populacional, foi efetuada de acordo com o utilizado por Audino (2017), por isso foram utilizadas as Equações 1 e 2.

$$
n \circ=\frac{1}{E 0^{2}}(1) ; \quad n=\frac{N n^{\circ}}{N+n^{\circ}}
$$

Onde: $\mathrm{N}$ é o Número de elementos da população; n é o tamanho da amostra; no é uma primeira aproximação para o tamanho da amostra; e Eo é o erro amostral tolerável.

A coleta da água (Figura 3) obedeceu aos padrões estabelecidos por Brandão et al. (2011) e complementado com a normativa descrita no Manual Prático de Análise de Água (FUNASA, 2013).

Figura 3. Padrão de Coleta do IQA e ICB, no Rio Ipixuna. Ipixuna do Pará. Pará.

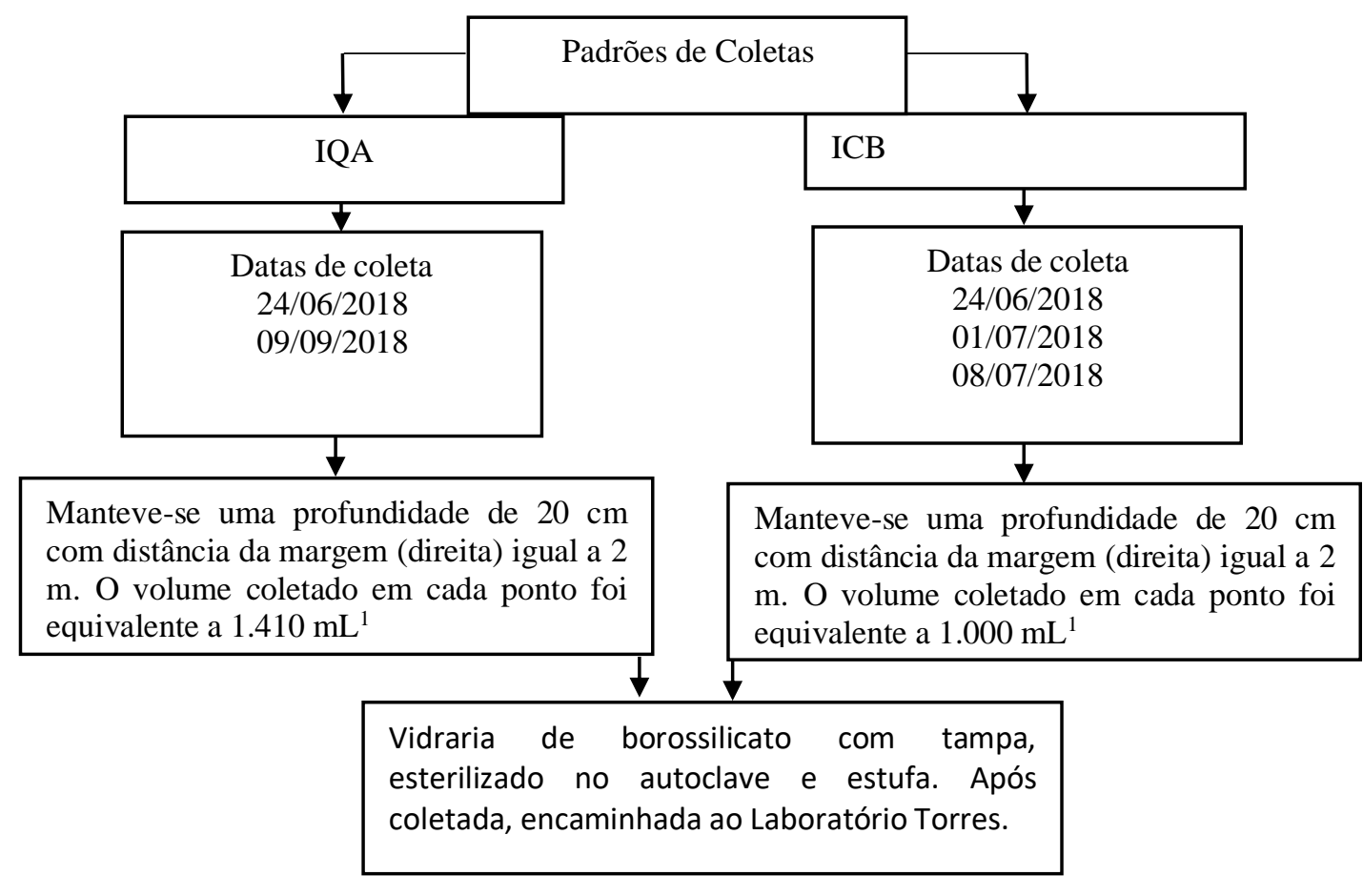

Legenda: ${ }^{1}$ Volume solicitado pelo laboratório. Fonte: Autores (2020).

Em seguida os frascos foram alocados em caixa isotérmica $(\mathrm{V}=28 \mathrm{~L})$, contendo gelo para conservar as propriedades físicas e químicas na temperatura ideal, ou seja, $4^{\circ} \mathrm{C}$ (ANA, 2011), e conduzidas para o Laboratório Torres localizado em Paragominas - Pará.

Essas análises ocorreram de acordo com os padrões preestabelecidos pela Standard Methods for the Examination of Water and Wastewater para análise de água e efluentes (APHA, 2011). Para a determinação do Índice de Qualidade da Água (IQA), foram adicionados “pesos” aos nove parâmetros da água. Em relação ao Índice das Condições de Balneabilidade (ICB) foi necessário analisar apenas quatro parâmetros (Tabela 2), em obediência à Resolução CONAMA 274 (Brasil, 2000). 
Tabela 2. Parâmetros em métodos utilizados para análises do IQA e ICB. Rio Ipixuna. Pará, Brasil.

\begin{tabular}{|c|c|c|c|c|}
\hline \multirow{2}{*}{ Parâmetros } & \multirow{2}{*}{ Técnicas efetuadas } & \multicolumn{2}{|c|}{ IQA } & \multirow{2}{*}{$\begin{array}{l}\text { ICB } \\
\text { Variáveis }\end{array}$} \\
\hline & & Variáveis & *Pesos (wi) & \\
\hline OD & Winkler & $\mathbf{X}$ & 0,17 & -- \\
\hline DBO & Incubação por 5 dias & $\mathbf{X}$ & 0,10 & -- \\
\hline $\mathbf{T}_{\mathrm{H} 2 \mathrm{O}}$ & Termometria & $\mathbf{X}$ & 0,15 & -- \\
\hline pH & Potenciômetro & $\mathbf{X}$ & 0,12 & $\mathbf{X}$ \\
\hline Turbidez & Espectrofotometria & $\mathbf{X}$ & 0,08 & $\mathbf{X}$ \\
\hline $\mathbf{N}_{\text {total }}$ & Espectrofotometria & $\mathbf{X}$ & 0,10 & -- \\
\hline$F_{\text {total }}$ & Espectrofotometria & $\mathbf{X}$ & 0,10 & -- \\
\hline Stotais & Gravimetria & $\mathbf{X}$ & 0,08 & -- \\
\hline E. coli & Bioquímica reacional & $\mathbf{X}$ & 0,15 & $\mathbf{X}$ \\
\hline
\end{tabular}

*Estabelecido pela CETESB (2017). Elaborada pelos autores partir de dados contidos na Resolução CONAMA 274 (Brasil, 2000).

\subsubsection{Secundários}

O levantamento de dados documentais, cujo recorte temporal de 12 anos (2010 a 2021), em links eletrônicos de acesso aberto: Portal Periódicos da Coordenação de Aperfeiçoamento do Pessoal de Nível Superior (CAPES); Science Direct, Scientific Eletronic Library Online (SciELO), Web Science, dentre outros. Para as normativas e legislações utilizadas, pois foram mantidas as datas das promulgações, bem como dos trabalhos pioneiros sobre a temática dessa pesquisa. Justifica-se esse período temporal em face da evolução do município ter avançado mais nesse período. Para essa seleção, foram utilizados quatro descritores seletivos: qualidade da água; balneabilidade; percepção ambiental da comunidade e deficiência do saneamento básico.

\subsection{Cálculos}

Os cálculos foram efetuados com a utilização de planilhas eletrônicas contidas em softwares especializados (Quadro 2).

Quadro 2. Softwares utilizados para cálculos diversos.

\begin{tabular}{|c|c|c|c|}
\hline Aplicações & Software & Versão, fabricante (ano) & Equações \\
\hline $\begin{array}{l}\text { Calcular o Índice da Qualidade } \\
\text { da Água } \\
\text { (IQA) }\end{array}$ & Qualigraf & $\begin{array}{c}\text { Versão } 1.17 \\
\text { FUNCEME (2015) }\end{array}$ & (3) \\
\hline \multicolumn{4}{|c|}{${ }^{1} \mathbf{I Q A}=\prod_{i}^{n} \boldsymbol{q}^{\boldsymbol{i}^{w i}}$} \\
\hline $\begin{array}{l}\text { Calcular o Índice de Condições } \\
\left.\text { da Balneabilidade ( }{ }^{2} \mathrm{ICB}\right)\end{array}$ & Excel & $\begin{array}{c}\text { Versão } 2016 \\
\text { Microsoft Corporation (2016) }\end{array}$ & Tabela 3 \\
\hline Média do ICB geral & Excel & $\begin{array}{c}\text { Versão } 2016 \\
\text { Microsoft Corporation (2016) }\end{array}$ & (4) \\
\hline \multicolumn{3}{|c|}{ 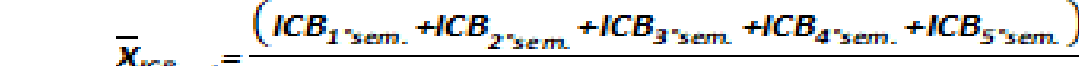 } & \multirow[t]{2}{*}{ (4) } \\
\hline \multicolumn{3}{|c|}{$\lambda_{\text {iCE }}=5$} & \\
\hline $\begin{array}{l}\text { Estatística descritiva: } \\
\text { frequência absoluta }(f i) ; \\
\text { frequência relativa }(f r \%) \text {; média } \\
\overline{(x)} \text { s e desvio padrão }(\sigma)\end{array}$ & Excel & $\begin{array}{c}\text { Versão } 2016 \\
\text { Microsoft Corporation (2016) }\end{array}$ & \\
\hline Elaboração de gráficos & OriginPro & $\begin{array}{c}\text { Versão } 9.0 \\
\text { OriginLab (2019) }\end{array}$ & \\
\hline
\end{tabular}


Legendas: "IQA é o (valor entre 0 e 100); $q_{i}$ é a qualidade do i-ésimo parâmetro (número entre 0 e 100 ); $w_{i}$ é o peso correspondente ao iésimo parâmetro (algarismo entre 0 e 1). 'Metodologia proposta por Lopes et al. (2014). Tal método tem como base "o mínimo operador", que reúne: concentração de $E$. coli, cianobactérias, pH e turbidez com base nos valores mínimos e máximos contida na Resolução CONAMA 274 (BRASIL, 2000). As tabulações dos dados foram efetuadas de acordo com o preconizado pelo Instituto Brasileiro de Geografia e Estatística (IBGE, 1993). Fonte: Autores (2020).

Tabela 3. Equações para o cálculo do ICB.

\begin{tabular}{lcl}
\hline \multicolumn{1}{c}{ Parâmetros } & Faixas & \multicolumn{1}{c}{ Equações (3) } \\
\hline $\boldsymbol{E}$. coli & $<800$ & $\mathrm{y}=2 \mathrm{E}-05 \mathrm{x}^{2}-0,0785 \mathrm{x}+101,82$ \\
(UFC/100mL) & $800 \leq 3157$ & $\mathrm{y}=-0,0208 \mathrm{x}+66,667$ \\
& $>3157$ & $\mathrm{q}=1$ \\
\hline & $0 \leq 10.000$ & $\mathrm{y}=2 \mathrm{E}-07 \mathrm{x}^{2}-0,0063 \mathrm{x}+96,834$ \\
Cianobactérias & $10.000 \leq 20.000$ & $\mathrm{y}=-0,0025 \mathrm{x}+75$ \\
$(\mathbf{c e l} / \mathbf{m L})$ & $20.000 \leq 100.000$ & $\mathrm{y}=-0,0003 \mathrm{x}+31$ \\
& $\mathrm{DC} \geq 100.000$ & $\mathrm{q}=1$ \\
\hline & $0 \leq 10$ & $\mathrm{y}=0,1644 \mathrm{x}^{2}-6,7602 \mathrm{x}+100,93$ \\
Turbidez & $10<100$ & $\mathrm{y}=0,0048 \mathrm{x}^{2}-1,0741 \mathrm{x}+60,259$ \\
(UT) & $\geq 100$ & $\mathrm{q}=1$ \\
& & \\
& $\leq 2$ & $\mathrm{q}=1$ \\
& $2 \leq 6$ & $\mathrm{y}=-6,0526 \mathrm{x}+100,79$ \\
pH & $6 \leq 9$ & $\mathrm{y}=-4 \mathrm{x}+90$ \\
& $9 \leq 12$ & $\mathrm{y}=0,0048 \mathrm{x}^{2}-1,0741 \mathrm{x}+60,259$ \\
& $\geq 12$ & $\mathrm{q}=1$ \\
\hline
\end{tabular}

Fonte: Adaptado de Lopes et al. (2014).

Após os cálculos, observou-se o preconizado por Lopes et al. (2014): o menor valor obtido, a partir dos valores situados abaixo do "satisfatório" para o ICB (E.coli; $\mathrm{pH}$; cianobactérias e turbidez) semanal, permite a identificação dos fatores limitantes à balneabilidade (Tabela 4).

Tabela 4. Enquadramento dos índices em classes qualitativas.

\begin{tabular}{|c|c|c|c|c|c|}
\hline PADRÕES & & & CLASSES & & \\
\hline IQA & $\begin{array}{l}\text { Ótima } \\
79<\text { IQA } \leq 100\end{array}$ & $\begin{array}{l}\text { Boa } \\
51<\mathrm{IQA} \leq 79\end{array}$ & $\begin{array}{l}\text { Regular } \\
36<\text { IQA } \leq 51\end{array}$ & $\begin{array}{l}\text { Ruim } \\
19<\text { IQA } \leq \\
36\end{array}$ & $\begin{array}{l}\text { Péssima } \\
\text { IQA } \leq 19\end{array}$ \\
\hline ICB & $\begin{array}{l}\text { Excelente } \\
100 \geq \mathrm{ICB} \geq 90\end{array}$ & $\begin{array}{l}\text { Muito boa } 90 \\
>\text { ICB } \geq 70\end{array}$ & $\begin{array}{l}\text { Satisfatória } 70> \\
\text { ICB } \geq 50\end{array}$ & $\begin{array}{l}\text { Imprópria } \\
50>\text { ICB } \geq 25\end{array}$ & $\begin{array}{l}\text { Muito } \\
\text { ruim } \\
25>\mathrm{ICB} \\
\geq 0\end{array}$ \\
\hline CONAMA & Excelente & Muito boa & Satisfatória & & \\
\hline 274/00 & $0<$ E. coli $\leq 200$ & $\begin{array}{l}200>E . \quad \text { coli } \\
\geq 400\end{array}$ & $400>$ E. coli $\geq 800$ & E. coli $800<$ & -- \\
\hline
\end{tabular}

Fontes: CETESB (2017); Lopes et al. (2014); CONAMA 274 (Brasil, 2000).

Complementou-se tudo isso com uma análise complementar, para justificar a variação dos parâmetros que apresentaram desconformidade com a legislação pertinente. 


\section{Resultados e Discussão}

\section{1 índice de qualidade da água - IQA}

Os dados obtidos e analisados quantitativamente sobre o IQA nos cinco pontos amostrais, para os períodos chuvoso e seco, indicaram que os valores médios situaram na faixa de 64 a 70 (Figura 4). Além disso, indicaram um valor de grandeza $(51<\mathrm{IQA} \leq 79)$, que permite classificar a qualidade da água do Rio Ipixuna como "boa".

Figura 4. Valores médios do IQA em cada ponto analisado. Rio Ipixuna, Pará, Brasil.

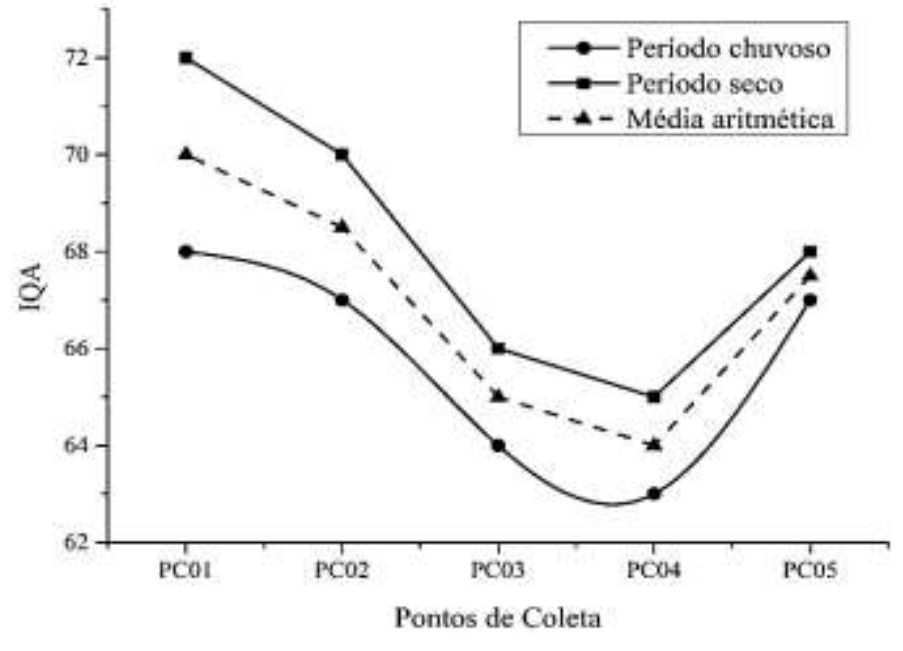

Fonte: Autores (2018).

A análise dos dados também indicou que, em PC01 (a montante), o valor médio do IQA (70,0) foi superior aos demais pontos. Isso ocorreu devido às características de vegetação mais preservada (em estado de restauração ecológica), distante do perímetro urbanizado, sem pressões antrópicas, e não possui descargas de efluente doméstico nesse local.

Pesquisa associada a esse fato, foi realizada por Poleto et al. (2010), no município de Ilha Solteira - SP, e os dados que eles obtiveram indicaram que o cenário atual de recursos hídricos, localizados distante do perímetro urbanizados, possui um processo poluitivo menor, devido ao baixo aproveitamento da água, que consequentemente, permite uma melhor qualidade da água. A pesquisa realizada em Ipixuna do Pará apresentou usos similares aos identificados naquela localidade e, por isso, a qualidade da água em PC01 apresenta boa qualidade.

Já em PC02, balneário com menor taxa de frequentadores, o valor da média para o IQA $(\bar{x}=68,5)$ foi inferior a PC 01. No primeiro, desaguam efluentes domésticos oriundos de dois conjuntos residenciais situados no curso médio dele. Em PC03, além da elevada frequência para balneabilidade, há também lançamentos desse tipo de efluente. O efeito disso é um odor esteticamente desagradável devido a decomposição de matéria orgânica porque existe o acumulo de resíduos sólidos. Em face desses acontecimentos, o valor médio do IQA $(\bar{x}=65,0)$ foi inferior a PC02.

Em relação ao PC04, a análise dos dados indicou o menor valor médio (IQA, $\bar{x}=64,0)$ em relação aos três anteriormente analisados. As causas disso, são: presença de bares, maior frequência à balneabilidade e lançamento de efluentes domésticos. Em relação a PC05, verificou-se que a vegetação em estado de regeneração natural é devido a heterogeneidade do dossel e, embora sofra pressões antrópicas advinda da urbanização, nesse ponto não ocorre despejo de efluente. Logo, o IQA mostrou tendência a elevação $(\bar{x}=67,5)$ e ficou bem próximo ao encontrado para $\mathbf{P C 0 2}(\bar{x}=68,5)$.

No município de Irati - PR, Andrade e Felchak (2009) realizam pesquisa sobre a qualidade da água em rios urbanos, e os dados indicaram que a principal causa da alteração da qualidade da água em trechos urbanos é oriunda do despejo inadequado de esgotos domésticos e sem nenhum tratamento prévio, devido à falta de saneamento básico e a inexistência de 
fiscalização dos órgãos competentes. Em face desses dados, nota-se similaridade com o ocorrido em Ipixuna do Pará, onde a causa dos valores médios do IQA em trechos urbanos são resultantes do despejo inadequado de esgoto doméstico.

No estudo efetuado por Alves et al. (2012), no rio Arari, Ilha de Marajó - PA, os autores concluiram que as águas desse rio são classificadas como "ruim e regular", em razão do pH ácido, baixas concentrações de oxigênio dissolvido, além do envolvimento de coliformes fecais. No rio Ipixuna, o IQA, mesmo com presença de descarga de efluentes a qualidade da água foi classificada como "boa".

Para o IQA $\mathrm{I}_{\text {médio, }}$ os dados obtidos e analisados para os cinco pontos, nos dois períodos sazonais, indicaram valores médios (chuvoso: $\bar{x}=68,5$; seco: $\bar{x}=65,8$ ) permitiram a qualificação da água nos pontos analisados, como "boa". Isso ocorreu devido aos parâmetros que compõe o IQA (OD, E. coli, Temperatura da água, $\mathrm{S}_{\text {totais, }}$, DBO e Turbidez) se enquadraram nos padrões legais da Resolução 357 (BRASIL, 2005). Vale ressaltar que no período seco houve tendência de redução (IQA = - 2,7), quando comparado ao período chuvoso. Logo, o despejo inadequado de esgoto no percurso urbano, o uso do solo, atividades pecuaristas as margens dos cinco pontos amostrais influenciam no IQA.

Gonçalves e Rocha (2016) efetuaram estudo sobre a influência do período chuvoso no IQA, em Ponta Grossa - PR, e concluíram que, nesse período, os valores de IQA são superiores quando comparados com a estação seca. Pois, a temperatura do corpo hídrico se mantém, logo, o OD concentra-se no interior dele, além disso, a decomposição da matéria orgânica é baixa e o uso intensivo da terra diminui. Tais conclusões são similares aos fatos ocorridos em Ipixuna do Pará.

\subsubsection{Analise complementar}

Aos dados obtidos e paragonados com a Resolução CONAMA 357 (BRASIL, 2005), indicaram que temperatura da água, OD, DBO, E. coli, turbidez e sólidos totais mantiveram dentro dos padrões preestabelecidos pela normativa vigente, enquanto, houve discrepância dos limites legais em pH, $\mathrm{N}_{\text {total }}$ e $\mathrm{F}_{\text {total }}$ (Tabela 5).

Tabela 5. Valores dos parâmetros de IQA, nas duas coletas de água. Rio Ipixuna, Pará, Brasil.

\begin{tabular}{|c|c|c|c|c|c|c|c|c|c|c|}
\hline PC & PC & OD & DBO & $\mathrm{T}_{\mathrm{H} 2 \mathrm{O}}$ & $\mathrm{pH}$ & Turbidez & $\mathrm{N}_{\text {total }}$ & $F_{\text {total }}$ & $\mathrm{S}_{\text {totais }}$ & E. coli \\
\hline & & \multicolumn{2}{|c|}{------mg/L------ } & ${ }^{0} \mathrm{C}$ & & $(U t)$ & \multicolumn{3}{|c|}{-----------(mg/L)----------- } & UFC/100mL \\
\hline PC & 01 & 6,8 & 1,4 & 26 & 6,0 & 4,9 & 1,5 & 0,1 & 12,0 & 200 \\
\hline PS & 01 & 6,2 & 1,5 & 25 & 5,3 & 4,8 & 1,3 & 0,2 & 10,3 & 50 \\
\hline \multicolumn{2}{|c|}{$\overline{\mathbf{X}}$} & 6,5 & 1,4 & 25,5 & 5,7 & 4,9 & 1,4 & 0,1 & 11,1 & 125 \\
\hline PC & 02 & 6,4 & 1,3 & 26 & 5,5 & 3,9 & 1,3 & 0,1 & 13,0 & 100 \\
\hline PS & 02 & 5,9 & 1,2 & 25 & 5,4 & 4,892 & 2,6 & 0,1 & 11,0 & 150 \\
\hline \multicolumn{2}{|c|}{$\overline{\mathbf{X}}$} & 6,2 & 1,3 & 25,5 & 5,5 & 4,395 & 2,0 & 0,1 & 12,0 & 125 \\
\hline PC & 03 & 6,1 & 1,3 & 26 & 5,6 & 5,0 & 1,7 & 0,1 & 12,0 & 500 \\
\hline PS & 03 & 5,7 & 1,8 & 25 & 5,4 & 4,5 & 2,0 & 0,2 & 10,5 & 200 \\
\hline \multicolumn{2}{|c|}{$\bar{X}$} & 5,9 & 1,5 & 25,5 & 5,5 & 4,8 & 1,9 & 0,1 & 11,2 & 350 \\
\hline PC & 04 & 6,2 & 1,4 & 26 & 5,2 & 4,0 & 1,8 & 0,1 & 11,00 & 300 \\
\hline PS & 04 & 5,9 & 2,3 & 25 & 5,5 & 6,2 & 2,5 & 0,2 & 10,6 & 250 \\
\hline \multicolumn{2}{|c|}{$\overline{\mathbf{x}}$} & 6,0 & 1,9 & 25,5 & 5,3 & 5,1 & 2,1 & 0,1 & 10,8 & 275 \\
\hline PC & 05 & 6,9 & 1,5 & 26 & 5,2 & 3,5 & 1,5 & 0,1 & 12,0 & 150 \\
\hline PS & 05 & 6,1 & 1,6 & 25 & 5,3 & 5,8 & 2,0 & 0,1 & 11,5 & 100 \\
\hline \multicolumn{2}{|c|}{$\overline{\mathbf{X}}$} & 6,5 & 1,6 & 25,5 & 5,3 & 4,6 & 1,7 & 0,1 & 11,8 & 125 \\
\hline
\end{tabular}

Legendas: PC - período chuvoso; PS - período seco; PC - pontos de coleta; OD - Oxigênio Dissolvido; DBO - Demanda Bioquímica de Oxigênio; $\mathrm{T}_{\mathrm{H} 2 \mathrm{O}}$ - Temperatura da água; pH - Potencial Hidrogeniônico; E. coli - Escherichia coli; N Notal - Nitrogênio total; Stotais - sólidos totais; Ftotal - Fósforo total. Fonte: Autores (2018). 


\subsubsection{Potencial Hidrogeniônico (pH)}

Em relação à análise do parâmetro pH, apenas na primeira coleta de água, em PC01, constatou-se valor qualificado como "satisfatório" $(6,0)$ aos parâmetros estabelecidos da legislação $(6,0$ a 9,0). Nas demais amostras analisadas, a faixa de pH abaixo do estabelecido, ou seja, as águas dos balneários estudados são ácidas e o maior valor médio de pH foi em PC01 ( $\bar{x}=$ 5,7). Então, as causas da alteração desse parâmetro são decorrentes da decomposição da matéria orgânica provinda da vegetação nativa em contato a água, constituída por galhos, folhas e trocos submersos e ao despejo inadequado de efluente no leito e às margens do rio.

A pesquisa desenvolvida por Lopes et al. (2010), em Carracas - MG, constataram valores de pH médios (5,4 a 5,5), e foram decorrentes de ácidos fúlvicos e húmicos oriundos da degradação da matéria orgânica presente na água (folhas, galhos e efluente domésticos), e aos pontos amostrais com lançamento de efluentes, estes apresentaram pouca variação, devido as mudanças de pH por processos bioquímicos. Tais conclusões são similares ao estudo ocorrido em Ipixuna do Pará.

\subsubsection{Fósforo total $\left(\mathrm{F}_{\text {total }}\right)$ e Nitrogênio total $\left(\mathbf{N}_{\text {total }}\right)$}

Em relação aos valores de Ftotal, na primeira coleta manteve-se constante em todos os pontos amostrais $(0,1 \mathrm{mg} / \mathrm{L})$. No segundo período de coleta, Ftotal variou tanto em PC01, quanto em PC03 e PC04 (0,2 mg/L). Dessa forma, nos cinco pontos, os valores obtidos foram superiores aos limites preestabelecidos $(0,05 \mathrm{mg} / \mathrm{L})$ pela Resolução CONAMA 357 (Brasil, 2005) Aos valores de $\mathrm{N}_{\text {total }}$, constatou-se que os maiores valores médios foram obtidos nos pontos com maior recepção de efluente doméstico (PC02 $\bar{x}=2,0 ; \mathbf{P C 0 3} \bar{x}=1,9 ; \mathbf{P C 0 4} \bar{x}=2,1)$. Essa resolução, $\mathrm{N}_{\text {total }}$ não tem valor padronizado. Todavia, o $\S 3^{\circ}$ do artigo $10^{\circ}$, diz que o valor não poderá ser superior a $2,2 \mathrm{mg} / \mathrm{L}$ em ambientes lóticos. Porém, no período seco de coleta, os níveis de $\mathrm{N}_{\text {total }}$ se elevaram em PC02 (2,6 mg/L) e PC04 (2,5 mg/L), não estando em conformidade com aquela resolução.

Acerca desses dois parâmetros analisados, Alves et al. (2012), em pesquisa realizada na ilha do Marajó, no Pará, constataram valores de $F_{\text {total }}(0,1$ e $0,2 \mathrm{mg} / \mathrm{L})$ iguais aos obtido na pesquisa em Ipixuna do Pará, e ainda, concluiu que, em períodos menos chuvosos favorece ao aumento das concentrações de $\mathrm{N}_{\text {total }}$, devido a descargas de esgotos domésticos. Logo, tanto $\mathrm{F}_{\text {total }}$ quanto $\mathrm{N}_{\text {total }}$ foram influenciados por drenagens pluviais de áreas de exploração pecuaristas, que faz uso de fertilizantes químicos e agrotóxicos, de excrementos bovinos, e de cargas veiculadas de esgotos domésticos (atividades fisiológicas e detergentes) no rio Ipixuna.

\section{2 Índice de condições da balneabilidade - ICB}

Os dados obtidos a analisados para os componentes do ICB nos cinco pontos analisados indicaram que, em três deles, a população de cianobactérias torna a qualidade da água imprópria para o banho (Tabela 6).

Tabela 6. Valores médios dos componentes do ICB nos cinco pontos analisados. Rio Ipixuna, Pará, Brasil.

\begin{tabular}{lcccccccc}
\hline \multicolumn{7}{c}{ Variáveis analisadas (médias) } \\
\hline Pontos & $\boldsymbol{E} . \boldsymbol{c o l i}$ & C & Ciano & C & Turb. & C & pH & C \\
\hline PC01 & 90,6 & E & 61,8 & S & 75,8 & MB & 4,6 & I \\
PC02 & 84,4 & MB & 52,8 & S & 79,0 & MB & 4,1 & I \\
PC03 & 77,7 & MB & 49,4 & I & 75,8 & MB & 4,5 & I \\
PC04 & 79,7 & MB & 44,7 & I & 77,8 & MB & 4,3 & I \\
PC05 & 86,5 & MB & 59,3 & S & 43,6 & MB & 4,5 & I \\
$\bar{x} \pm \sigma$ & $83,6 \pm 5,3$ & & $53,6 \pm 7,0$ & & $70,4 \pm 15,4$ & & $4,4 \pm 0,2$ & \\
\hline
\end{tabular}

Legendas: E. coli = Escherichia coli; $\mathrm{C}$ = Classificação; Ciano = Cianobactérias; Turb. = Turbidez; pH = potencial Hidrogeniônico. $\mathrm{E}=$ Excelente; MB = Muito Bom; S = Satisfatório. Fonte: Autores (2020) 
Para E. coli, a análise dos dados obtidos indicou que PC03 apresentou menor $\mathrm{ICB}_{E}$. coli . Isso ocorreu devido a descarga de efluente doméstico de sarjetas e águas pluviais, através de bueiros a cerca de 200 metros a montante. Na pesquisa realizada no mesmo rio, por Gutjahr et al. (2014) para mapeamento das fontes de contaminação desse corpo hídrico, os autores identificaram vários pontos de entrada de agente poluente (efluente) no Rio Ipixuna. Logo, PC03 é um deles.

Já no estudo efetuado por Martins (2012), em Belo Horizonte - MG, quanto a balneabilidade nesse tipo de corpo hídrico, verificou que a ocorrência de presença de E. coli, indica principalmente contaminação antrópica, pois, são oriundas de contaminação unicamente fecal de fonte sanitária, já que estão presentes no trato gastrointestinal de animais ou homem. Desta forma, a grande concentração desses patógenos, pode indicar lançamento de efluente doméstico no local.

Também, na pesquisa realizada por Queiroz e Rubim (2015) em Manaus - AM, indicou que a descarga de efluentes no rio onde há balneabilidade oferece fatores de riscos principalmente na exposição à agentes patogênicos, pois lá, foi identificado precariedade no saneamento básico e, portanto, os riscos de adquirir uma doença de veiculação hídrica prevalecem. Os valores de E. coli na pesquisa em Manaus, não apresentaram grande variação porque a maior concentração delas está localizado próximo a zona de interceptação do efluente com o corpo hídrico, não encontrados nos balneários daquela cidade, e o fator de diluição e movimento das águas são variáveis que afetam na concentração dos microrganismos.

Mas em Ipixuna do Pará, os valores de E. coli no PC03 não apresentaram altos valores, já que a capacidade de autodepuração do rio Ipixuna, está ativa. Ressalte-se que, nessa área, há uma fonte de lançamento de efluente. Contudo o estado ambiental, nesse local, permitiu na redução do valor de E. coli, o que corrobora o estudo efetuado em Manaus - AM.

Para as cianobactérias, PC04, foi notório a grande quantidade de população de cianobactérias relacionado com a excessiva quantidade de nutrientes oriundos de efluentes domésticos que desaguam nesse ponto. Além disso, na segunda semana, em que o ICB cian. apresentou classe muito ruim, a temperatura média do ambiente constava $33^{\circ} \mathrm{C}$ sem ocorrência de precipitação e pH ácido $(5,3)$.

Sobre a produção de toxinas por essas bactérias, Cheung et al. (2013) estudaram os impactos dessa substância na saúde pública, e concluíram que a proliferação delas (bactérias) é altamente prejudicial à saúde humana. Todavia, deve-se identificar primeiro a espécie e, em seguida, reações tissulares como: erupção cutânea (pele vermelha) ou com comichão devido a produção de hepatotoxinas, neurotoxinas, citotoxinas.

No estudo realizado em Ipixuna do Pará, indicou excessivo crescimento de cianobactérias em PC04, os valores encontrados foram considerados um grande risco a saúde dos banhistas, pois ultrapassaram os limites máximos permitidos, haja vista que foi comprovado pelo estudo dos impactos de toxinas das cianobactérias que estes microrganismos podem causar efeitos adversos a saúde do homem desde a uma simples irritação na pele a óbito.

Quanto ao $\mathrm{pH}$ nos cinco pontos analisados, a análise dos dados obtidos indicou que nesses locais, a água está imprópria para balneabilidade, tanto para os componentes isolados ou no ICB geral. Em relação a origem, os dados obtidos indicaram que as alterações dessa variável hídrica, podem ser devido a: assoreamento, contaminação por metais pesados ou por efluentes. De acordo com a pesquisa realizada por Amaral e Silva (2017) no município de Porto Velho - AM, o pH $<7$, em águas balneárias pode representar riscos ao bem-estar do banhista, além de causar irritações na pele e no globo ocular.

No PC02, foi constatado que o $\mathrm{pH}$ indicou água ácida $(4,6>\mathrm{pH}>5,72)$ inapropriada ao banho. A justificativa à redução dele, é a presença de espécies arbóreas (reflorestamento) que colaboram diariamente na quantidade de matéria orgânica no leito do rio, e baixo movimento das águas em relação aos demais pontos de coleta.

A pesquisa realizada por Kolm e Miquelante (2011) no município de Pontal - PR, indicou que a redução do pH foi provocada de duas maneiras: 1) lançamento de efluente doméstico e 2) presença/ acúmulo de matéria orgânica nas margens oriundos da vegetação da mata ciliar do corpo hídrico, sendo carreados para dentro do corpo hídrico. Além disso, a 
discrepância entre valores de Parâmetros em locais distintos seria influenciada pela variação da velocidade de renovação da água do corpo hídrico.

No PC05, em todas as semanas estudadas, houve indicação de acidez $(5,15>\mathrm{pH}>5,67)$ na água. Todavia, não foi identificado fontes de poluição severa que influenciaria na alteração dos valores desse potencial. De acordo com estudo realizado por Amaral e Silva (2017) no município de Iranduba - AM, apresentou valores de dessa variável limnológica abaixo do valor "satisfatório" (4,85 a 4,95), caracterizado pelo autor como natural, porém, o autor ressalta que as alterações para os valores dela, podem ocorrer devido a eventos naturais, como a dissolução de rochas, oxidação de matéria orgânica ou absorção de gases da atmosfera.

Quanto aos valores para: 1) ICB semanal, o menor deles foi identificado na $4^{\mathrm{a}}$ semana (PC04) de análise e o máximo ocorreu na $1^{\text {a }}$ semana (PC01); 2) ICB geral, o menor valor ocorreu no PC04. Todavia os cinco pontos analisados não apresentam águas com qualidade permissível à balneabilidade (Tabela 7).

Tabela 7. Valores Semanais e Geral para o ICB, nos cinco pontos analisados. Rio Ipixuna, Pará, Brasil.

\begin{tabular}{lcccccc}
\hline \multicolumn{3}{c}{ Variáveis analisadas (médias) } & & \\
\cline { 1 - 3 } & \multicolumn{3}{c}{ Semanal } & & Geral \\
\hline Pontos & Vmáx. & Vmín. & & C \\
\hline PC01 & 50,4 & $1^{\mathrm{a}}$ & 43,1 & $5^{\mathrm{a}}$ & 46,4 & I \\
PC02 & 43,3 & $4^{\mathrm{a}}$ & 32,3 & $5^{\mathrm{a}}$ & 41,7 & $\mathrm{I}$ \\
PC03 & 49,2 & $3^{\mathrm{a}}$ & 37,5 & $1^{\mathrm{a}}$ & 42,4 & $\mathrm{I}$ \\
PC04 & 43,6 & $4^{\mathrm{a}}$ & 1,0 & $2^{\mathrm{a}}$ & 33,8 & I \\
PC05 & 47,0 & $4^{\mathrm{a}}$ & 39,2 & $2^{\mathrm{a}}$ & 43,6 & $\mathrm{I}$ \\
$\bar{x} \pm \sigma$ & $46,7 \pm 3,2$ & & $36,2 \pm 24,4$ & & $41,5 \pm 4,7$ & \\
\hline
\end{tabular}

Legendas: Vmáx.= Valores Máximos; Vmín. = Valores mínimos; $C$ = Classificação. Fonte: Autores (2020).

Sobre o ICB geral, Lopes et al. (2014) efetuaram estudo no Alto Rio das Pedras - MG, e concluíram que nas condições de valores inferiores para o ICB geral, estabelecidos em duas normativas padrões (BRASIL, 2000; CETESB, 2017) utilizadas peara esse tipo de classificação, ou seja, água balneária "impropria", deve-se suspender temporariamente o banho na área através da sinalização, realizar amostragem da água diariamente e identificar a fonte de contaminação.

A análise dos dados obtidos para o ICBgeral, que o PC01 apresentou melhor ICB geral (46.4) em relação a todos os pontos analisados, isso ocorreu devido a localização dele estar em zona rural e não urbana, logo, a descarga de efluentes é bem menor e ainda não está recebendo resíduos oriundos de defensivos agrícolas (Figura 5).

Figura 5. ICB geral de todos os pontos. Rio Ipixuna, Pará, Brasil.

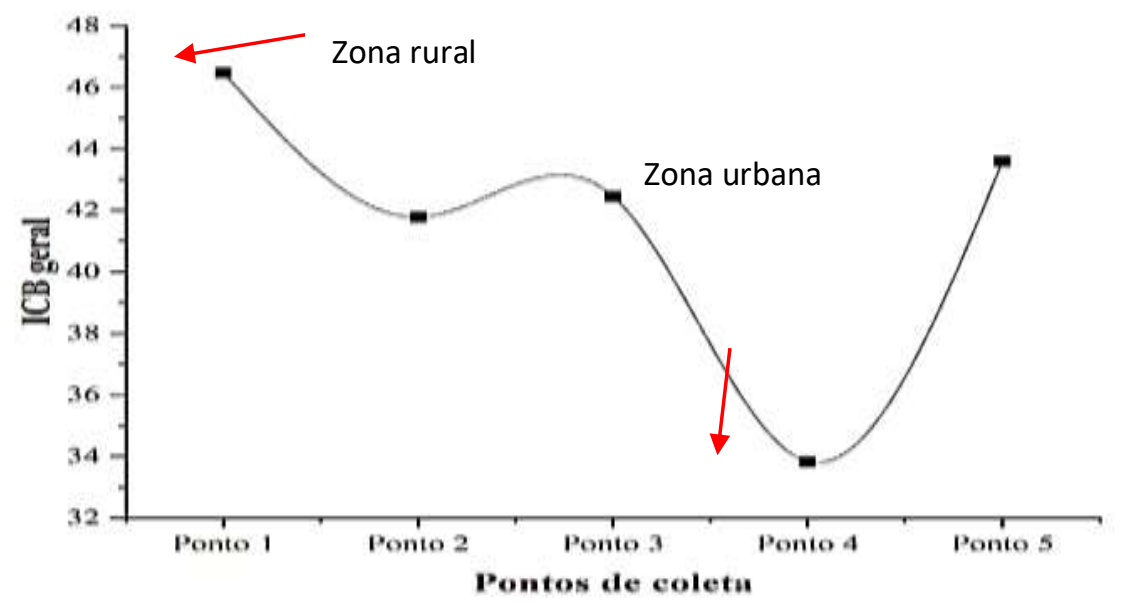

Fonte: Autores (2020). 
Quanto aos "fatores limitantes" para que o ICB fosse ideal, após análise dos dados obtidos, foram identificados duas variáveis ( $\mathrm{pH}$ e cianobactérias) com valores abaixo do "satisfatório". Por isso, em PC01, somente o $\mathrm{pH}$ foi o fator limitante (Tabela 8).

Tabela 8. Fatores limitantes ao ICB por ponto de coleta. Rio Ipixuna, Pará, Brasil.

\begin{tabular}{|c|c|c|c|c|}
\hline $\begin{array}{l}\text { Ponto } \\
\text { De } \\
\text { coleta }\end{array}$ & $\begin{array}{l}\text { Faixa } \\
\text { do ICB }\end{array}$ & Classe & $\begin{array}{c}\text { Recomendação } \\
\text { (Lopes et al., 2014) }\end{array}$ & Fator limitante \\
\hline PC01 & $50 \geq 25$ & impropria & $\begin{array}{l}\text { Suspensão do uso através de } \\
\text { sinalização temporária. Amostragem } \\
\text { diária (intervalo mínimo de 24h) e } \\
\text { identificação da origem da } \\
\text { contaminação }\end{array}$ & $\mathrm{pH}$ \\
\hline PC02 & $50 \geq 25$ & impropria & Idem & $\mathrm{pH}$ e cianobactérias \\
\hline PC03 & $50 \geq 25$ & impropria & Idem & $\mathrm{pH}$ e cianobactérias \\
\hline PC04 & $50 \geq 25$ & impropria & Idem & pH e cianobactérias \\
\hline PC05 & $50 \geq 25$ & impropria & Idem & pH e cianobactérias \\
\hline
\end{tabular}

Legendas: PC-Ponto de Coleta; ICB - Índice de Condições da Balneabilidade. Fonte: Autores (2020).

Vale ressaltar que após vistoria na área, pode-se constatar que, nos pontos estudados, o corpo hídrico não apresenta mata ciliar conservada em sua totalidade, conforme faixa nominal determinada na Lei n. ${ }^{\circ} 12.651$ (Brasil, 2012), e em algumas porções, apresenta conjuntos domiciliares nas margens do rio, o que influencia diretamente na conservação da qualidade da água.

Na classificação como fator limitante ao pH, em estudos pretéritos e pioneiros (Libânio, 2008; Von Sperling, 2005), os pesquisadores afirmam que o ideal para essa variável em águas superficiais de acordo com o segundo autor, situam-se entre 6,0 e 8,5. Já o segundo chama a atenção para a fatores naturais associados a essa variável: dissolução de rochas absorção de gases atmosféricos, oxidação de matéria orgânica, fotossíntese e despejo de esgotos domésticos. Os dois últimos podem ter contribuído para as variações do pH, já que ambos foram identificados nos cinco pontos analisados do rio Ipixuna.

\subsection{Percepção ambiental e da qualidade da água dos banhistas.}

Os dados obtidos e analisados sobre esses temas, indicaram que, dos 134 banhistas a maioria dos indivíduos amostrados $(n=85 ; 77,27 \%)$, afirmaram que a água do rio não é boa e, os demais ( $n=49 ; 44,54 \%)$ afirmaram que a qualidade da água é ruim. Com isso, sugeriram que ela melhoraria se o efluente da cidade não fosse despejado diretamente no rio e se evitasse o lançamento de resíduos sólidos nas margens e no leito do rio onde são utilizados para balneabilidade, e propuseram diversas soluções (Figura 6). 
Figura 6. Propostas dos indivíduos amostrados à melhoria da qualidade da água do Rio Ipixuna, Pará, Brasil.

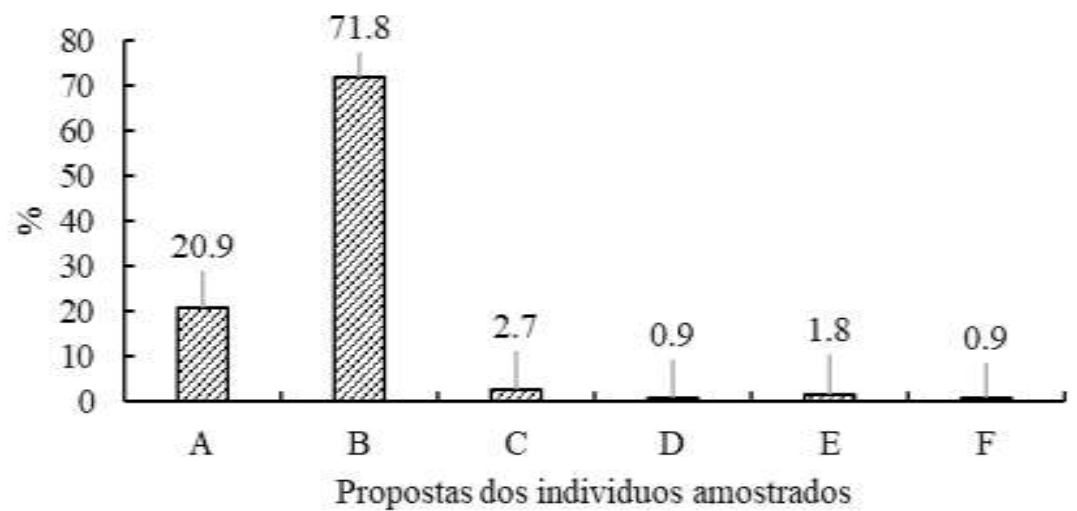

Legendas: A - Remover os resíduos B - Remover o efluente C- Não desmatar a mata ciliar D- Saneamento básico E- Diminuir a poluição FProteção a nascente e conscientização. Fonte: Autores (2020).

Dentre as ações sugeridas, a remoção de efluentes, ou seja, presença de saneamento básico, é atualmente, um dos problemas que mais aflige comunidade e gestores dos 5.546 municípios brasileiros e que já é objeto de estudos no Brasil. Sobre esse tema, Evaristo et al. (2017), realizaram pesquisas na comunidade de Candidópolis, Itabira - MG, e os dados que eles obtiveram, indicaram que $40 \%$ das unidades residenciais apresentam esgotamento sanitário, $13 \%$ sabem da existência mas as residências deles não ligadas à rede. Identificaram também que ainda ocorre grande quantidade de lançamento de efluentes nos corpos hídricos dessa região.

Outra observação foi direcionada a aquisição de doenças após o banho nesse rio. A maioria dos indivíduos amostrados ( $n=105 ;$ 95, 45\%), alegaram nunca ter adquirido doença (Ex.: verminose, diarreia, amebíase, hepatites, cólera, gastrenterite). Porém, o estudo realizado por Queiroz e Rubim (2016) assevera que a suscetibilidade a doenças após o banho em águas contaminadas depende do tempo, forma de exposição a água, concentração de enteropatógenos na água e nas margens e principalmente do tipo de indivíduo, pois, os mais suscetíveis a doenças são crianças, idosos e grávidas, devido à baixa imunidade por fatores fisiológicas. Neste caso, em Ipixuna do Pará, o maior número de usuários do rio Ipixuna, nos pontos estudados, que utilizam a água para banho, são jovens entre 15 e 35 anos, homens e mulheres, ou seja, público menos suscetível a doenças.

Quanto a ocorrência de descarga de efluente no rio Ipixuna identificada pelos indivíduos amostrados, percebeu-se que os dados para E. coli $(83,6 \pm 5,3)$ classificar as águas nos cinco pontos, como "excelente e muito boa". Isso pode estar associado a capacidade de autodepuração do rio Ipixuna que, apesar de todas as agressões ambientais antrópicas, ainda é funcionando ao contento. ade reduzida.

Foi verificado também que no PC01 (Figuras 7a; 7b), PC02 (Figura 7c) e PC04 (Figuras 7c; 7d), que é o mais frequentado pelos indivíduos amostrados, há frequência quanto à disposição inadequada de resíduos sólidos encontrados às margens do rio Ipixuna, como plásticos e vidros oferecem riscos à saúde dos banhistas. No caso de segundo, o risco e vulnerabilidade a acidentes aos banhistas é elevado, uma vez que pode causar ferimentos como é o caso do vidro por ser cortante e riscos de enforcamento pelo plástico para a fauna aquática especialmente peixes. A maioria dos resíduos é de origem domiciliar ou de limpeza urbana de classe II-B conforme NBR 10.004 (Brasil, 2004). 
Figura 7. PC01: a) Resíduos sólidos no leito; b) as margens do rio Ipixuna. PC02. c) esteritamento de margem e resíduos sólidos; PC04. D) Bueiro acéu aberto e danificado com efluentes adentando ao corpo hídrico e e) Coleto de lixo destampado e próximo à margem direita do rio Ipixuna.. Ipixuna do Pará, Pará, Brasil.

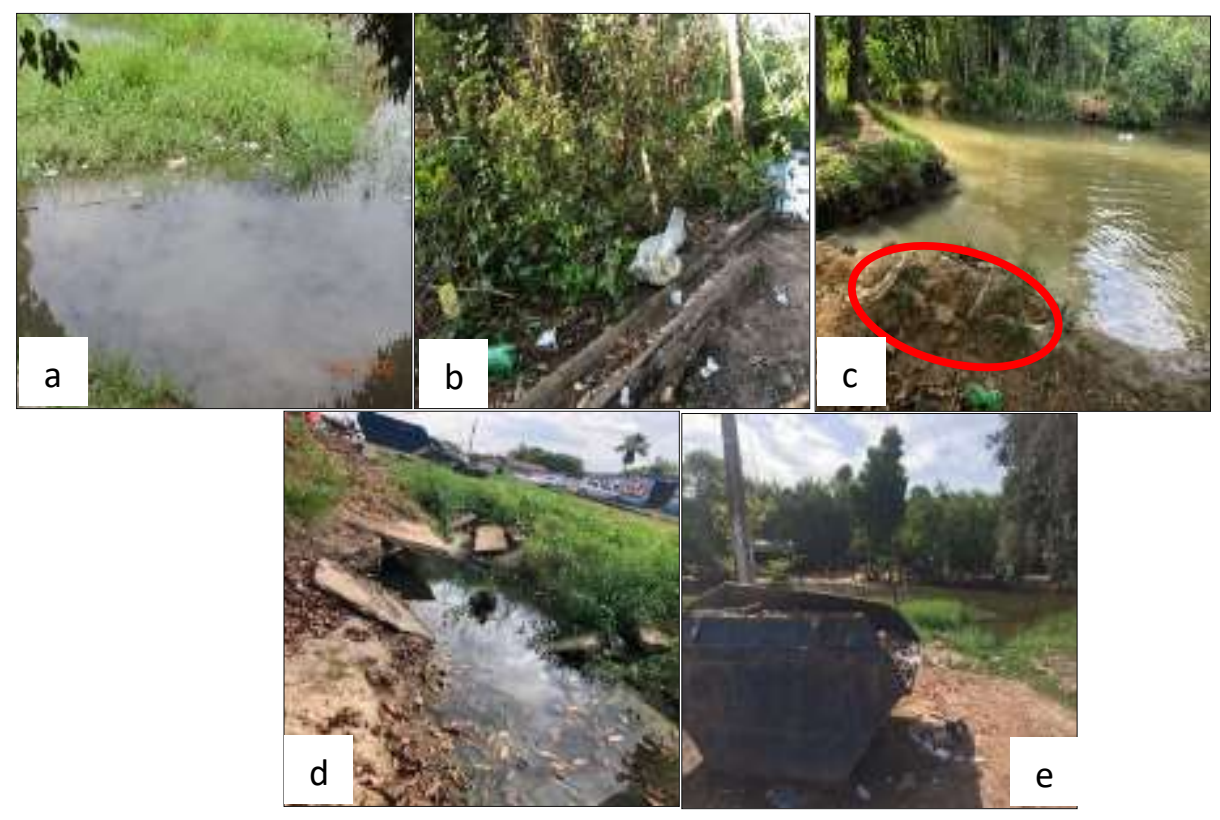

Fonte: Autores (2018).

$\mathrm{Na}$ análise dos dado obtidos, bem como nas visitas in loco foi constatado que o PC02 é o local que recebe menos banhistas em relação aos outros balneários estudados, mesmo assim foram encontrados resíduos naquele local como há uma estreitamento margina e presença de palmáceas, os riscos de alagamentos, comprometimento da vazão no período chuvoso é real.

Nesse local, uma minoria dos indivíduos amostrados $(n=3 ; 60 \%)$ informaram que já sentiram irritações após o banho nesse local. Acerca dessa irritação, Lopes et al. (2013), estudaram as águas brasileiras recreacionais, e concluíram que o pH ideal para elas é igual a 7,4, mas esse valor é equivalente ao $\mathrm{pH}$ do liquido lacrimal, e isso acarreta alterações na saúde humana. Porém, desconfortos como as irritações nos olhos, narina, pele e outros, podem ser cessados após lavagem com água de $\mathrm{pH}$ normal $(6,5<\mathrm{pH} \leq 8,5)$.

Sobre a bueiro e o container a $10 \mathrm{~m}$ da margem do rio Ipixuna, no período chuvoso, o chorume gerado no interior do container e lixiviado para o canal central desse rio. Essa ação foi objeto de pesquisa realizada por Ribeiro et al. (2015), em Jaraguá do Sul - SC, e os dados que eles obtiveram, indicaram que o esgoto doméstico é rico em nitrogênio $(\mathrm{N})$ e fósforo $(\mathrm{P})$ orgânico e inorgânico. Logo, a grande preocupação é que estes nutrientes favorecem o crescimento excessivos de algas.

Assim também, o estudo efetuado por Lima (2017) sobre a ocorrência e toxicidade de cianobactérias em Surubim $\mathrm{PE}$, concluiu que além das altas concentrações de nutrientes, a temperatura alta, baixa precipitação e pH alcalino. Por isso, em relação do rio Ipixuna, recomenda-se que as autoridades municipais promovam monitoramento constante até que se resolva o problema do saneamento básico nesse local.

\section{Conclusão}

Quanto a classificação para a água do Rio Ipixuna foi classificada qualitativamente, nos pontos amostrados, como boa. Tal fato é decorrente dos parâmetros (OD, E. coli, Temperatura da água, $\mathrm{S}_{\text {totais, }}$ DBO e Turbidez) estarem em consonância com os padrões pré-estabelecidos pela CONAMA. Porém, as variáveis $\mathrm{pH}, \mathrm{N}_{\text {total }}$ e $\mathrm{F}_{\text {total }}$ foram influenciadas pela ausência de 
um sistema de saneamento básico, que consequentemente, toda carga de efluente doméstico está sendo despejado no Rio Ipixuna, sem tratamento prévio. Além disso, o uso do solo as margens do rio, influenciou na qualidade de água dele, o que reduziu IQA.

Quanto a balneabilidade, os pontos estudados apresentaram condições improprias ao banho devido à alta concentração de cianobactérias e água ácida o que gera riscos à saúde pública e a saúde da população usuária do corpo hídrico. Por isso, é de suma importância que se realize inspeções e monitoramento nas áreas balnearias constantemente, haja vista que os dados da pesquisa indicaram resultados preocupantes sobre as condições da balneabilidade.

Além disso, os indivíduos amostrados, como representantes sociais que vivenciam os aspectos ambientais, utilizam a água do Rio Ipixuna à balneabilidade, mesmo com despejo de efluente doméstico e comercial, apenas por falta de alternativas de outras áreas para lazer. Por isso, o senso crítico dos indivíduos influenciaram na percepção de que devem conservar o corpo hídrico, e solicitar junto aos órgãos competentes, melhorias Parara mitigação ou minimização dos impactos sob a qualidade da água e da balneabilidade.

Portanto, a fim de evitar surtos de doenças, devido ao uso mais frequente, a balneabilidade, é fundamental o monitoramento da qualidade da água, pois é parte integrante da gestão ambiental na conservação dos recursos hídricos e política urbana ao assegurar o bem-estar da população do município e a qualidade ambiental.

Os dados aqui contidos podem servir para monitoramentos futuros desses balneários quanto a qualidade da água, bem como para determinação pelas autoridades ambientais, como "área imprópria para banho" e, com isso conservar a qualidade de vida de comunidade local. Além disso, poderá nortear estudos para a "zona da mistura", e contribuir para melhor identificar os efluentes que ora estão sendo despejados no rio Ipixuna.

\section{Referências}

Alves, I. C. C., El-Robrini, M., Santos, M. L. S., Monteiro, S. M., Barbosa, L. P. F., \& Guimarães, J, T. (2012). Qualidade das águas superficiais e avaliação do estado trófico do Rio Arari (Ilha do Marajó, norte do Brasil). Acta Amazônia,. 42(1), 115-124. https://doi.org/10.1590/S0044-59672012000100014

Amaral, C. T., \& Silva, F. S. A. (2017). Qualidade da água em um igarapé balneário na Amazônia: estudo de caso em Porto Velho. Revista de geografia e interdisciplinaridade, 3(8), 251-267. https://doi.org/10.5216/rev.\%20geoambie.v0i12.25985

ANA. (2011). Guia Nacional de coleta e preservação de Amostras: água, sedimentos, comunidades aquáticas e efluentes líquidos. ANA.

Andrade, A. R., \& Felchak, I. M. (2009) Sa poluição urbana e o impacto na qualidade da água do rio das ANTAS - IRATI-PR. GEO AMBIENTE ON-LINE, 1(12), 108-32 HTTPS://DOI.ORG/10.5216/REV.\%20GEOAMBIE.V0I12.25985

APHA. (2011). Standard Methods for the Examination of Water and Wastewater.

Audino, V. (2017) [Tese]. Elaboração de um instrumento sobre a percepção ambiental da população urbana Parara a sustentabilidade de cidades. Universidade Federal de Outo Preto http://www.repositorio.ufop.br/bitstream/123456789/8854/1/DISSERTA\%C3\%87\%C3\%83O_Elabora\%C3\%A7\%C3\%A 3oInstrumentoPercep\%C3\%A7\%C3\%A3o.pdf.

Borges, D. M. (2014). Método dedutivo, indutivo ou comparativo. Qual o mais adequado à pesquisa do direito internacional do meio ambiente? Planeta Amazônia. 6,85-101. https://periodicos.unifap.br/index.php/planeta/article/view/1146/DanielN6.pdf

Brandão, C. J., Botelho, M. J. C., Sato, M, I, Z., \& Lamparelli, M. C. (Org) (2011). Guia nacional de coleta e preservação de amostras: água, sedimento, comunidades aquáticas e efluentes líquidos. (2 ed). CETESB; Brasília: ANA.

BRASIL. (2000). Resolução CONAMA n. ${ }^{2} 274$. http://www.mma.gov.br/port/conama/legiabre.cfm?codlegi=272

BRASIL. (2004). NBR ABNT n. ${ }^{\circ}$ 10.004. Resíduos sólidos - Classificação. ABNT. https://www.abntcatalogo.com.br/norma.aspx ?ID=936

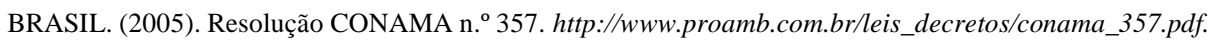

BRASIL. (2012). Resolução n. 466.http://www.planalto.gov.br/ccivil_03/_Ato2011-2014/2012/Lei/L12651.htm

BRASIL. (2016). Resolução n. ${ }^{\circ}$ 510. http://conselho.saude.gov.br/resolucoes/2016/reso510.pdf.

Campos, J. S., \& Cunha, H. F. A. (2015). Análise comparativa de parâmetros de balneabilidade em Fazendinha, Macapá-AP. Biota Amazônia, 5(4)110-118. http://dx.doi.org/10.18561/2179-5746/biotaamazonia.v5n4p110-118

CETESB. (2017). Índices de Qualidade das Águas. Cetesb, www.cetesb.sp.gov.br 
Cheung, M. Y., Liang, S, \& Lee, J. (2013). Toxin-producing cyanobacteria in freshwater: A review of the problems, impact on drinking water safety, and efforts for protecting public health. Journal of Microbiology, 51(1), 1-10. http://dx.doi.org/10.1007/s12275-013-2549-3

Cordeiro, I. M. C. C., Rangel-Vasconcelos, L. G. T., Schwartz, G., \& Oliveira, F. A. (Org.) (2017) Nordeste Paraense: Panorama geral e uso sustentável das florestas secundárias. EDUFRA.

Evaristo, G. V., Cordeiro, J., Alvarenga, C. A., Oporto, L. T., Quintão, P. L., Calazans, G, M., \& Cordeiro, J, L. (2017). Saneamento básico e percepção ambiental: um estudo realizado na comunidade Candidópolis em Itabira, Monas Gerais. Research, Society and Development, 4(1), 45-61. file:///D:/Downloads/28-Artigo_Arquivo-85-1-10-20161213.pdf

FUNASA. (2013). Manual Prático de Análise de Água. (4 ed.), Funasa.

FUNCEME. (2015). QualiGraf. Versão 1.17. Fortaleza: Fundação Cearense de Meteorologia e Recursos Hídricos. http://www3.funceme.br/qualigraf/mi/midia/show/3

Gonçalves, D. R. P., \& Rocha, C. H. (2016). Indicadores de qualidade da água e Padrões de uso da terra em bacias hidrográficas no estado do Paraná. Pesquisa Agropec, 51(9),1172-1183. http://dx.doi.org/10.1590/s0100-204x2016000900017.

Gutjahr, A. L. N., Araújo, L. J. B., Matos, E. S., Braga, C. E. S. (2014). Diagnóstico e mapeamento das fontes de contaminação do rio Ipixuna, estado do Pará, Brasil. Enciclopédia Biosfera,10(19),2092-2107. http://www.conhecer.org.br/enciclop/2014b/CIENCIAS\%20BIOLOGICAS/ diagnostico\%20e\%20mapeamento.pdf

IBGE. (1993). Normas de apresentação tabular. (3a ed.), IBGE.

IBGE. (2010). Cidade. https://cidades.ibge.gov.br/brasil/Para/ipixuna-do-Parara/Paranorama.

Kolm, H. E., \& Miquelante, F. A.(2011). Indicadores microbiológicos de poluição fecal na desembocadura da Gamboa olho d'água, Paraná: subsídio para o monitoramento da balneabilidade no Brasil. Publications UEPG: Ciências Biológicas e da Saúde, 17(1), 21-35. 10.5212/Publ.Biologicas.v.17i1.0003

Libânio, M. (2008). Fundamentos de qualidade e tratamento de água. Campinas: Átomo.

Lima, V. H. M. (2017). Cianobactérias em reservatórios do estado de Pernambuco: ocorrência e toxicidade. HOLOS, (4), 111-124. https://doi.org/10.15628/holos.2017.4470.

Lopes, F. W. A., \& Magalhães-Junior, A. P. (2010). Influência das condiç̃̃es naturais de pH sobre o Índice de Qualidade da Água (IQA) na bacia do Rio de Carrancas. Revista Geografias, 6(2),134-147. https://periodicos.ufmg.br/index.php/geografias/article/view/13301/10533.

Lopes, F. W. A., Magalhães-Junior, A. P., \& Von-Sperling, E. V. (2013). Balneabilidade em águas doces no Brasil: riscos à saúde, limitações metodológicas e operacionais. Hygeia. 9(16), 28 - 47. http://www.seer.ufu.br/index.php/hygeia/article/view/22268

Lopes, F. W. A., Magalhães-Junior, A. P., \& Von-Sperling, E. V. (2014). Metodologia Parara avaliação de condições de balneabilidade em águas doces no Brasil. Revista brasileira de recursos hídricos, 19(4),124-136. 10.21168/rbrh.v19n4.p124-136

Macedo-Silva, W., Tchaicka, L., \& Sá-Silva, J. R. (2016). Representações Sociais e Percepção Ambiental: A Balneabilidade de Praias de São Luís e São José de Ribamar, Maranhão, Brasil. Revista Rosa dos Ventos, 8 (4), 405-418. file:///D:/Downloads/4283-18402-1-PB.pdf

Martins, L. K. L. A. (2012) [Dissertação]. Contribuições para monitoramento de balneabilidade em águas doces no Brasil. Universidade Federal de Minas Gerai. http://www.smarh.eng.ufmg.br/defesas/1005M.PDF

Matias-Pereira, J. (2016). Manual de metodologia da pesquisa científica. (4ed.). Atlas

MICROSOFT CORPORATION. (2016). Project for Windows. Versão Excel 2016. Microsoft Corporation, Albuquerque. New México.

Moura, D., \& Fermino, F. S. (2014). Aspectos da qualidade da água para abastecimento público na represa Paulo de Paiva castro/sistema Cantareira-São Paulo/SP. Revista Metropolitana de Sustentabilidade, 4(2), 96-109. http://189.2.181.205/index.php/rms/article/view/237

OrinLab. (2019). Graphics and analysis. Versão pro-9.0. OriginLab Corporation, Northampton. https://www.originlab.com/index.aspx?go=Supp ort\&pid=1960

Perdigão, G. S., Cordeiro, J., Calazans, G. M., Ferreira, D. L. G., Nascimento, F. D., Brandão, J M. S., \& Guimarães, J. C. S. (2018) Análise da qualidade da água de atrativos turísticos naturais localizados na comunidade Cabeça de boi Itambé do Mato Dentro (MG). Research, Society and Development, 7(6), 01-25. https://doi.org/10.17648/rsd-v7i6.256

Pereira, A. S., Shitsuka, D. M., Parreira, F. J., \& Shitsuka, R. (2018). Metodologia da pesquisa científica. UFSM.

PNMA. (2008). Índice e indicadores de qualidade da água-Revisão da Literatura. 2008. http://www.cprh.pe.gov.br/downloads/indice-agua-volume1.pdf

Poleto, C.; Carvalho, S. L., \& Matsumoto, T. (2010). Avaliação da Qualidade da Água de uma microbacia hidrográfica no munícipio de Ilha Solteira (SP). HOLOS Environmet, 10(1), 95-110. https://doi.org/10.14295/holos.v10i1.4241

Queiroz, C. P. S., \& Rubim, M. A. L. (2016). Avaliação da condição de balneabilidade na orla urbana de Manaus/AM/Brasil. Scientia Amazonia. 5(2),24-33. http://scientia-amazonia.org/wp-content/uploads/2016/09/v5-n2-24-33-2016.pdf

Ribeiro, M. R. P., Simioni, D., \& Pitol-Filho, L. (2015). Uso de tanino Parara remoção de nutrientes do esgoto sanitário da estação de tratamento de efluentes Nereu Ramos em Jaraguá do Sul - SC. E-Tech: Tecnologias para Competitividade Industrial, 8(1), 161-174. https://doi.org/10.18624/e-tech.v8i1.487 
Research, Society and Development, v. 10, n. 4, e36810414131, 2021

(CC BY 4.0) | ISSN 2525-3409 | DOI: http://dx.doi.org/10.33448/rsd-v10i4.14131

Rodrigues, M. L., Malheiros, T. F., Fernandes V., Daros, T. D. (2012). A percepção ambiental como instrumento de apoio na gestão e na formulação de políticas públicas ambientais. Saúde Social, 21(3), 96-110. http://dx.doi.org/10.1590/S0104-12902012000700009

Sakamoto, C. K., \& Silveira, I. O. (2014). Como Fazer Projetos de Iniciação Científica. São Paulo: Paulus.

Scandelai, A. P. J., Solina, M. R. F., \& Souza, A. T. (2012). Avaliação da balneabilidade e qualidade da água da represa laranja-doce no município de Martinópolis-SP. Revista Colloquium Exactarum. 4(2),31 - 36. http://revistas.unoeste.br/index.php/ce/article/view/800.

SEMAS. (2018). Simlam Público. http://monitoramento.semas.Para.gov.br/simlam/index.htm.

Teixeira, K. L., Silva, G., \& Correa, D. L. (2020). Análise da percepção ambiental de professores e alunos da Escola Municipal Raimu ndo Nonato Sobrinho em Paragominas, Estado do Pará, Brasil. Research, Society and Development, 9(8), e886986479. http://dx.doi.org/10.33448/rsd-v9i8.6479

Von Sperling, M. (2005). Introdução à qualidade das águas e ao tratamento d esgotos. (3a ed.). UFMG. 